\title{
Management of patients with pulmonary mycobacteriosis in France: a multicenter retrospective cohort study
}

Pascale Bemer ${ }^{1}$, Olivia Peuchant ${ }^{2}$, Hélène Guet-Revillet ${ }^{3}$, Julien Bador ${ }^{4}$, Charlotte Balavoine ${ }^{5}$, Damien Basille ${ }^{6,7}$, Guillaume Beltramo ${ }^{8}$, François-Xavier Blanc ${ }^{9}$, Elodie Blanchard ${ }^{10}$, Sarah Boulanger ${ }^{11}$, Anne Bourgoin ${ }^{12}$, David Boutoille ${ }^{13}$, Emmanuelle Cambau $^{14,15}$, Frédérique Canis $^{16}$, Didier Caparros ${ }^{17}$, Anne Carricajo ${ }^{18}$, Christian Carrière ${ }^{19}$, Gérard Couetdic ${ }^{20}$, Francis Couturaud ${ }^{21}$, Jean-Charles Dalphin ${ }^{22}$, Tristan Degot ${ }^{23}$, Marion Desquiens ${ }^{6}$, Gilles Devouassoux ${ }^{24}$, Jean-Marie Duez ${ }^{4}$, Oana Dumitrescu ${ }^{25}$, Magali Dupuy-Grasset ${ }^{26}$, Alice Gaudart ${ }^{27}$, Marjolaine Georges ${ }^{8}$, Cendrine Godet ${ }^{28}$, Sylvain Godreuil ${ }^{19}$, Aurélie Guillouzouic ${ }^{1}$, Farida Hamdad-Daoudi ${ }^{29}$, Geneviève Héry-Arnaud ${ }^{30}$, Christelle Koebel ${ }^{31}$, Aurore Lagrange ${ }^{6}$, Philippe Lanotte ${ }^{32}$, Sylvain Marchand-Adam ${ }^{5}$, Faïza Mougari ${ }^{14,15}$, Marlène Murris ${ }^{33}$, Isabelle Patry ${ }^{20}$, Michèle Pérouse de Montclos ${ }^{25}$, Laurent Raskine ${ }^{14,15}$, Karine Risso ${ }^{34}$, Christine Segonds ${ }^{3}$, Dominique Sicard ${ }^{27}$, Dominique Terru ${ }^{19}$, Anne Vachée ${ }^{35}$, Jean-Michel Vergnon ${ }^{36}$, Christian Martin ${ }^{37}$, Frédéric Schramm ${ }^{31}$ and Claire Andrejak ${ }^{6,7^{*}}$ (1)

\begin{abstract}
Background: Recent studies report very low adherence of practitioners to ATS/IDSA recommendations for the treatment of nontuberculous mycobacteria pulmonary disease (NTM-PD), as well as a great variability of practices. Type of management could impact prognosis.

Methods: To evaluate management and prognosis of patients with NTM-PD cases with respect to ATS recommendations, we conducted a multicenter retrospective cohort study (18 sentinel sites distributed throughout France), over a period of six years. We collected clinical, radiological, microbiological characteristics, management and outcome of the patients (especially death or not).

Results: 477 patients with NTM-PD were included. Respiratory comorbidities were found in $68 \%$ of cases, tuberculosis sequelae in $31.4 \%$ of patients, and immunosuppression in $16.8 \%$ of cases. The three most common NTM species were Mycobacterium avium complex (60\%), M. xenopi (20\%) and M. kansasii (5.7\%). Smear-positive was found in one third of NTM-PD. Nodulobronchiectatic forms were observed in $54.3 \%$ of cases, and cavitary forms in $19.1 \%$ of patients. Sixty-three percent of patients were treated, $72.4 \%$ of patients with smear-positive samples, and $57.5 \%$ of patients with smear-negative samples. Treatment was in adequacy with ATS guidelines in $73.5 \%$. The 2-year mortality was $14.4 \%$. In the Cox regression, treatment $(H R=0.51)$, age ( $H R=1.02)$, and $M$. abscessus (3.19) appeared as the 3 significant independent prognostic factors.
\end{abstract}

\footnotetext{
*Correspondence: andrejak.claire@chu-amiens.fr

${ }^{6}$ Department of Respiratory Diseases, Amiens University Hospital, CHU

Amiens, 80054 Amiens Cedex 1, France

Full list of author information is available at the end of the article
} original author(s) and the source, provide a link to the Creative Commons licence, and indicate if changes were made. The images or other third party material in this article are included in the article's Creative Commons licence, unless indicated otherwise in a credit line to the material. If material is not included in the article's Creative Commons licence and your intended use is not permitted by statutory regulation or exceeds the permitted use, you will need to obtain permission directly from the copyright holder. To view a copy of this licence, visit http://creativecommons.org/licenses/by/4.0/. The Creative Commons Public Domain Dedication waiver (http://creativeco mmons.org/publicdomain/zero/1.0/) applies to the data made available in this article, unless otherwise stated in a credit line to the data. 
Conclusion: These findings highlight the adequacy between French practices and the ATS/IDSA guidelines. Treatment was associated with a better survival.

Keywords: Nontuberculous mycobacteria, Mycobacterium xenopi, Mycobacterium avium complex, Prognosis, Management

\section{Background}

Nontuberculous mycobacteria pulmonary disease (NTM-PD) is not notifiable in France, as well as in most of the world. A large amount of epidemiological information remains unavailable. The microbiological diagnosis, even insufficient, is essential to make the diagnosis of infection. The clinical significance of a single positive sputum specimen in culture is difficult to estimate. It is important to follow the recommendations that at least two sputa or one bronchoalveolar lavage be culture-positive to consider microbiological criteria for NTM-PD $[1,2]$. To do this, it is essential to correctly identify NTM at the species level [3]. The cost of management of NTM-PD has been evaluated four-fold higher than that for matched control, related to hospitalization for $63 \%$ and antibiotic treatment for $22 \%$ [4].

A comparison between different countries showed that nodulobronchiectatic forms were more frequent in Japan than in Europe (59.8\% vs $39.2 \%$, respectively), and that moderate to severe clinical forms were less common in Japan than in Europe (31\% to $2 \%$ vs. $59 \%$ to $19 \%$, respectively) [5]. Patients were more often treated in Europe than in Japan (68\% vs $43 \%$, respectively). In this study, it appears that in Europe, Italian and Spanish patients were more than six times as likely to be treated than patients in France. The most influential factors for treating NTM-PD were age $>60$ years and severe clinical signs [5]. Two recent studies reported very low adherence of practitioners to ATS/IDSA treatment recommendations, particularly for Mycobacterium avium complex (MAC) and $M$. abscessus species, as well as a great variability of practices $[5,6]$. But these studies have been performed with questionnaires fulfilled by physicians. It is difficult to know who are these physicians and if these physicians are representative of all physicians who take care of NTM-PD patients. The other point of view is to analyze management of NTMPD patients and to compare to ATS/IDSA guidelines.

The purpose of this study was to evaluate management and prognosis of French patients with NTM-PD according to the 2007 ATS/IDSA recommendations over a period of six years, from January 2009 to December 2014. This study also described an overview of NTM-PD epidemiology in France.

\section{Methods}

This study was designed as a multicenter, retrospective, observational, cross-sectional study of patients aged more than 18 years and with NTM-PD, conducted according to the STROBE guidelines. The study protocol was approved by institutional review board and ethics committee (PI2018_843_0049). We gave written information on the study to each patient. In case of opposition to participate, patient was not included. The potential opposition is indicated in the medical record.

The Mycobacteria Medical (MycoMed) Study Group is a French network of 18 microbiological laboratories. The main objectives of the MycoMed Study Group are i/ to promote exchanges on laboratory practices and diagnostic approach in Mycobacteriology as part of laboratory accreditation, ii/ to initiate clinical-biological studies. Two previous studies of this Group analyzed incidence of MAC pulmonary disease between 2000 and 2002 and incidence of NTM-PD in HIV-negative patients from 2001 to $2003[7,8]$.

Patients $\geq 18$ years-old were included from January 2009 through December 2014 in 18 French Hospitals belonging to the MycoMed network.

All patients with at least one positive respiratory sample with NTM were eligible but only patients meeting the 2007 ATS/IDSA criteria after reviewing medical records were included. Patients with cystic fibrosis were excluded from the study. We have chosen 2007 ATS/IDSA criteria instead of 2017 BTS and 2020 ATS/IDSA/ERS/ESCMID, as our last was included in 2015, before publications of these 2 recent guidelines [2, 9].

Demographic, bacteriological and clinical and radiological data were obtained from medical records. For the primary survival analysis, the date of each patient's first positive specimen was used to ascertain comorbidity history. This allowed us to avoid comorbidity ascertainment bias introduced by differential survival times.

Respiratory specimens were decontaminated using the NALC-NaOH method. Microscopic examination was performed by Zielh-Neelsen staining, and specimens were inoculated onto liquid culture medium (mainly BD BACTEC $^{\mathrm{TM}}$ MGIT $^{\mathrm{TM}} 960$ system, Becton Dickinson) and a solid culture medium (mainly Löwenstein-Jensen). NTM identification at the species level was based on molecular characterization using commercial kits: AccuProbe ${ }^{\circledR}$ system (Gen-Probe, Inc., USA), INNO-LiPA Mycobacteria 
system (Innogenetics, Belgium), and GenoType Mycobacterium system (Hain Lifescience, Germany). Partial gene sequencing (rpoB/hsp65/16S-23S internal transcribed spacer, 16S rRNA) was less used. Since 2013, identification by matrix-assisted laser desorption/ionization time-of-flight mass spectrometry began to be carried out in some laboratories. In case of discrepancies or failures of identification, strains were sent to the French national reference center for mycobacteria.

We decided to group $M$. intracellulare and $M$. chimaera as some centers did not do at this time difference between the two species. For the same reason, we will present results for $M$. abscessus complex and not for each subspecies.

After descriptive analysis, univariate analysis was done for qualitative variables, Pearson's $\mathrm{Chi}^{2}$ or Fisher exact test and for quantitative variables, Student t-test or Wilcoxon rank test. We ascertained mortality from the medical records. Follow-up time was computed from the index date that defined an NTM disease episode until the date of death, migration, last hospital consultation, 3 years after index date, or $1^{\text {st }}$ June 2017, whichever came first. We used Kaplan-Meier analysis with log-rank testing to calculate and compare crude cumulative survival according to study variables, and Cox regression (univariate and multivariate survival analysis). Statistical analyses were performed using SAS version 9.1 software.

\section{Results}

During the period study, 568 NTM-PD were included. Among them 91 were excluded because of lack of radiologic data (87 cases) or identification of two different NTM species (4 cases). Overall, the remaining 477 cases (53.3\% of males) met the 2007 ATS/IDSA criteria for NTM-PD, and were included. The median age was 65 years [range 18-96].

MAC comprised the majority $(286 / 477,60 \%)$ of all NTM findings ( $M$. avium, $\mathrm{n}=149 ;$ M.intracellulare, $\mathrm{n}=134$; MAC without subspecie identification, $\mathrm{n}=3$ ), followed by, M. xenopi (94/477, 19.7\%), M.kansasii (27/477, 5.7\%), M.abscessus complex (18/477,3.8\%) M.fortuitum complex (17/477, 3.6\%) (M. fortuitum $(\mathrm{n}=13 ;$ M. chelonae, $\mathrm{n}=4)$. Other unfrequent NTM species were identified in 5.4\% (26/477) of cases: $M$. simiae $(\mathrm{n}=10), M$. malmoense $(\mathrm{n}=4), M$. genavense, M. scrofulaceum and $M$. szulgai in two cases for each species while $M$. arupense, M. florentinum M. heckeshornense, $M$. interjectum, M. lentiflavum and M. shimoidei were only isolated once. In the remaining 9 cases, NTM could not be identified at the species level.

\section{Clinical characteristics}

MAC patients were a majority of female (56.2\%) whereas $M$. xenopi and $M$. kansasii patients were a majority of males $(60.9 \%$ and $70.4 \%$, respectively). Sixty-eight percent of patients had respiratory comorbidities (chronic obstructive pulmonary disease, bronchiectasis) and $31.4 \%$ had tuberculosis sequelae. Few patients (16.8\%) had immunosuppression, mainly because of essentially systemic corticosteroids, immunosuppressive drugs or cancer. Forty-one patients (8.6\%) were HIV-positive and only $7.7 \%$ of them had immunosuppression (less than 200 $\left.\mathrm{CD} 4 / \mathrm{mm}^{3}\right)$.

\section{Radiographical findings}

More than half of patients $(259 / 477,54.3 \%)$ presented nodulobronchiectatic pattern (Table 1). Cavities were reported on $19.1 \%$ of cases while other radiological findings (such as pleural effusion or interstitial lesions) were found in $26.6 \%$ of NTM-PD. For this $26.6 \%$, lesions are not the classically pattern described in ATS/IDSA 2007. We considered them as NTM-PD, as all these patients underwent a complete evaluation, and the only possible diagnosis was NTM-PD despite the atypical radiological presentation. Nevertheless, a misclassification bias is always possible. This limit reflects one usual problem in real life.

Table 1 Radiological findings according to the NTM species

\begin{tabular}{lllll}
\hline & $\begin{array}{l}\text { Smear-positive } \\
\mathbf{N b}(\%)\end{array}$ & $\begin{array}{l}\text { Cavitary forms } \\
\mathbf{N b}(\%)\end{array}$ & $\begin{array}{l}\text { Nodulo-bronchiectatic } \\
\text { Forms } \\
\mathbf{N b}(\%)\end{array}$ & $\begin{array}{l}\text { Other findings } \\
\mathbf{N b}(\%)\end{array}$ \\
\hline Mycobacterium avium complex $(\mathrm{n}=286)$ & $98(34.3)$ & $46(16.1)$ & $169(59.1)$ & $71(24.8)$ \\
Mycobacterium xenopi $(\mathrm{n}=94)$ & $39(41.5)$ & $32(34.0)$ & $40(42.6)$ & $22(23.4)$ \\
Mycobacterium kansasii $(\mathrm{n}=27)$ & $11(40.7)$ & $7(25.9)$ & $15(55.6)$ & $5(18.5)$ \\
Mycobacterium abscessus complex $(\mathrm{n}=18)$ & $11(61.1)$ & $2(11.1)$ & $10(55.6)$ & $6(33.3)$ \\
Mycobacterium fortuitum complex $(\mathrm{n}=17)$ & $3(17.6)$ & $0(0.0)$ & $8(47.1)$ & $9(52.9)$ \\
Other species $(n=35)$ & $13(37.1)$ & $4(11.4)$ & $17(48.6)$ & $14(40.0)$ \\
Total $(\mathrm{n}=477)$ & $175(36.7)$ & $91(19.1)$ & $259(54.3)$ & $127(26.6)$ \\
\hline
\end{tabular}


The different NTM had significant difference in term of radiological pattern $(p=0.001$; Table 1$)$. Nodulobronchiectatic pattern was the predominant radiological pattern in subjects infected by MAC (59.1\%), M. kansasii (55.6\%) and $M$. abscessus complex (55.6\%). A slightly higher rate of nodulobronchiectatic pattern (42.6\%) than cavitations (34\%) was observed in patients with NTM-PD cause by M. xenopi. In the 17 NTM-PD du to M. fortuitum complex, other forms were reported in $52.9 \%$ of cases and nodulobronchiectatic in $47.1 \%$ of cases.

\section{Microbiological results}

\section{Bacteriological load among NTM species}

Smear-positive were found in $36.7 \%$ of the culture-positive specimens Interestingly, results depended on NTM species: $61.1 \%$ of specimens with $M$. abscessus complex were smear-positive, $41.5 \%$ for $M$. xenopi, $40.7 \%$ for M. kansasii, $34.3 \%$ for MAC and $17.6 \%$ for M. fortuitum complex.

\section{Samples recovered}

The median number of positive sample was two with variations from 1 to 11 positive specimens. For the 132 patients with only one positive sample, the specimen was always a bronchoalveolar lavage. When compared with patients with at least two positive samples, only 28 patients had a smear-positive specimen in the patients with unique positive BAL subgroup $(21.2 \%$ vs. $42.6 \%$ $(n=147 / 345), p<0.0001)$. These patients, with a unique positive BAL, had significantly less often a cavitary form ( $7.6 \%$ versus $23.5 \%, p<0.0001$ ) and have been treated less frequently ( $48.5 \%$ vs. $68.4 \%)$.

\section{Treatment (Table 2)}

Treatment data were available for 464 patients (Table 2). Overall, 62.9\% (292/464) of patients were treated. Patients with smear-positive specimens received more often treatment than those smear-negative specimens
( $72.4 \%$ vs $57.5 \%$, respectively $p=0.001)$. About two-third of subjects with MAC NTM-PD were treated, ranging from $76.0 \%$ in smear-positive cases to $62.5 \%$ in smearnegative cases $(p=0.02)$. Patients infected with M. xenopi were treated in $66.7 \%$ of smear-positive and $52.7 \%$ of smear-negative cases. Three-quarters of patients with $M$. kansasii or M. abscessus complex lung disease were treated regardless of smear-positivity.

Patients with NTM-PD due to $M$. fortuitum complex were treated in $23.5 \%$ of cases, mostly when specimens were smear-positive. These result were concordant with the last ERS/ATS/IDSA/ESCMID guidelines where it is suggested that initiation of treatment is preferred rather than watchful waiting, in the context of positive acid-fast bacilli sputum smears [2].

Treatment was in adequacy with 2007 ATS/IDSA guidelines in $73.5 \%$ of cases [1]. Eighty-nine percent of patients were treated with at least 3 drugs for more than 12 months in $75.1 \%$ of cases). Clarithromycin was used in $90.5 \%$ of MAC infections, $76.5 \%$ of M. xenopi and $84.6 \%$ of $M$. abscessus complex infections. Amikacin was mostly used in $M$. abscessus complex infections (58.3\% vs. $11.6 \%$ in MAC group and $8.3 \%$ in M. xenopi). Clarithromycin appeared as the most used macrolides in France, probably because it is the only one with an official indication for NTM treatment. Rifampicin and ethambutol were used in a vast majority of NTM-PD cases except those caused by M. abscessus complex.

\section{Outcome}

For the 418 patients with available data, the 2-year mortality was $14.4 \%$. In survival univariate analysis, smear result did not constitute a pejorative prognostic factor (HR 1.33 [0.78-2.26], Table 3, Fig. 1). Radiological form seemed not to be a prognostic factor. Treatment, age, and M. abscessus appeared as the 3 significant independent prognostic factors (Table 3) in the Cox regression.

Table 2 Distribution of treated patients according to the species and the results of microscopy

\begin{tabular}{|c|c|c|c|}
\hline & \multicolumn{3}{|l|}{ Treated patients } \\
\hline & Total available data & $\begin{array}{l}\text { Positive-smear results } \\
\text { N/A* }(\%)\end{array}$ & $\begin{array}{l}\text { Negative-smear results } \\
\mathrm{N} / \mathrm{A}^{*}(\%)\end{array}$ \\
\hline Mycobacterium avium complex & 280 & $73 / 96(76.0)$ & $115 / 184(62.5)$ \\
\hline Mycobacterium xenopi & 53 & $24 / 36(66.7)$ & $29 / 55(52.7)$ \\
\hline Mycobacterium kansasii & 18 & $8 / 11(72.7)$ & $10 / 13(76.9)$ \\
\hline Mycobacterium fortuitum complex & 4 & $2 / 3(66.7)$ & $2 / 14(14.3)$ \\
\hline Mycobacterium abscessus complex & 13 & $8 / 11(72.7)$ & $5 / 7(71.4)$ \\
\hline Other species & 16 & $8 / 13(61.5)$ & $8 / 21(38.1)$ \\
\hline Total & 292 & $123 / 170(72.4)$ & 169/294 (57.5) \\
\hline
\end{tabular}

$\mathrm{N} / \mathrm{A}^{*}$ : number of results among available data 
Table 3 Survival analysis, according to Cox regression

\begin{tabular}{|c|c|c|c|c|}
\hline & Non adjusted HR [Cl 95\%] & $p$ & $\begin{array}{l}\text { Adjusted HR } \\
\text { [CI 95\%] }\end{array}$ & $p$ \\
\hline Age & $1.02[1.01-1.04]$ & 0.02 & $1.02[1.01-1.04]$ & 0.04 \\
\hline Female & $0.73[0.42-1.27]$ & 0.27 & & \\
\hline Respiratory diseases & $0.99[0.54-1.83]$ & 0.99 & & \\
\hline Past mycobacterial diseases & $1.56[0.89-2.71]$ & 0.11 & & \\
\hline Cavitary disease & $0.84[0.42-1.66]$ & 0.61 & & \\
\hline Positive smear & $1.33[0.78-2.26]$ & 0.30 & & \\
\hline \multicolumn{5}{|l|}{ NTM specie } \\
\hline MAC & Reference & & Reference & \\
\hline M.xenopi & $1.33[0.68-2.60]$ & 0.40 & $1.21[0.59-2.49]$ & 0.61 \\
\hline M. abscessus & $2.64[1.03-6.78]$ & 0.04 & $3.19[1.22-8.32]$ & 0.02 \\
\hline M. kansasii & $0.69[0.16-2.88]$ & 0.61 & $1.12[0.20-3.45]$ & 0.83 \\
\hline Others & $1.16[0.41-3.29]$ & 0.78 & $1.02[1.01-1.04]$ & 0.83 \\
\hline Treatment & $0.47[0.27-0.83]$ & 0.009 & $C[0.28-0.92]$ & 0.03 \\
\hline
\end{tabular}

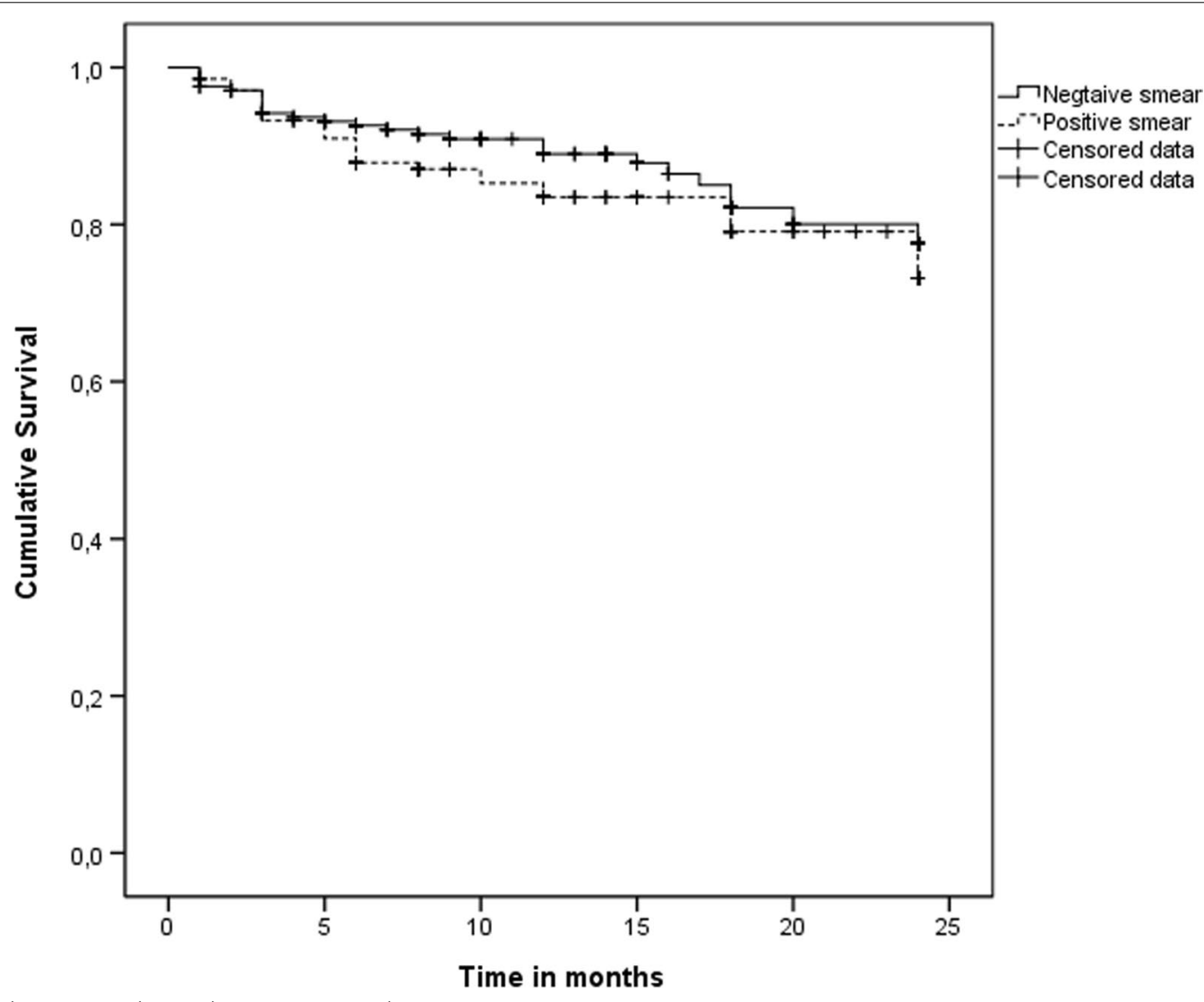

Fig. 1 Cumulative survival according to smear results

\section{Discussion}

Previous studies on NTM-PD are often general reviews mainly on the MAC complex [3, 10], or epidemiological studies based on laboratory data without clinical or radiological criteria $[11,12]$. Few cohort studies met ATS criteria $[13,14]$.

Our cohort included 477 patients who met the 2007 ATS/IDSA criteria for NTM-PD from 18 centers between 
2009 and 2014. Only two previous French studies reported data on 101 pulmonary MAC infections from 2000 to 2002, and on 262 NTM-PD from 2001 to 2003 according to the 1997 ATS criteria $[7,8]$. Our study is one of the biggest cohort studies of NTM diseased patients and allows us to have real conclusions about NTM-PD epidemiology and management in France.

Unfortunately, this study did not include all NTM-PD cases in France as only 18 centers participated, and does not permit to calculate the exact incidence and prevalence in France. Nevertheless, these 18 centers from the MycoMed network are among the biggest hospitals in France. One other limitation was the delay between the last included patients and the final analysis. Indeed, as it is retrospective study, we needed some administrative authorizations, and some time to give information to all concerned patients.

The diagnostic practices are homogeneous and standardized in these 18 centers, responding to published recommendations $[15,16]$, and identical to European practices [11]. Solid and liquid culture media were used as recommended [15]. The majority of NTMs were identified at the species level, most often using line probe hybridization, more rarely on-demand sequencing, or recently mass spectrometry $[15,16]$.

The following quality criteria can be highlighted for our cohort: i/ less than $2 \%$ of the strains could not be identified to the species level, ii/ it does not contain any contaminating species such as $M$. gordonae or $M$. terrae complex [1], iii/ finally very few pulmonary $M$. fortuitum complex infections, most often considered as non-pathogenic, were included [17].

In our cohort, the species distribution of NTM was close to that reported earlier in France [8] and more recently in a survey study of NTM in the European Union, which included France [18]. MAC was the commonest group of cultured organisms, as reported worldwide [18]. While studies showed that $M$. avium was the predominated subspecies recovered from human specimens [7, 18 ] in Europe, we found a similar number of $M$. avium and $M$. intracellulare isolates in our cohort. M. xenopi, followed by M. kansasii, were the second and the third species, respectively, the most frequently encountered in France. In the collaborative study of the NTM-NET network, M. abscessus complex and M. kansasii were the second and the third species, respectively.

The analysis of radiological and microbiological aspects of pulmonary NTM highlighted the variability associated with the species, and with the study period. Regarding MAC, the two-series meeting the ATS 1990 criteria of Obayashi and Wright reported a percentage of directsmear positive patients greater than $50 \%$, especially in the case of upper lobe cavitary lesions $[13,19]$. In the cohort of Wright [17], microscopy examination of pulmonary NTM due to MAC, M. abscessus and M. kansasii was positive in 58\%, 51\% and 78\% respectively. By comparison, in two subsequent studies of MAC meeting the 2007 ATS criteria, the percentages of cavitary lesions and positive direct examinations were $18 \%$ and $31 \%$ in the study of Boyle [12], and $20 \%$ and $35 \%$ in the study of Ito [20]. Our cohort was characterized by $19.1 \%$ of cavitary lesions and $36.7 \%$ of smear-positive results, similar to previous studies $[14,20]$.

The decrease of these two criteria is probably due to the lack of positive direct examination in the 2007 ATS criteria.

In our cohort, we found a high (61\%) percentage of smear-positive samples and a small (11\%) percentage of cavitary lesions in NTM-PD due to the $M$. abscessus complex. In comparison, the Wright study also reported a high percentage of positive direct examinations of $51.3 \%$ in NTM due to M. abscessus [19]. Specific studies were conducted on $M$. kansasii lung infections. In the Wright series, 29 (78.4\%) of 37 specimens positive in culture for $M$. kansasii were smear positive. The 37 specimens concerned only 8 patients for whom the radiological data were not known [19]. M. kansasii is an NTM so far known to present a similar clinical picture to that of pulmonary tuberculosis with fibrocavitary lesions in the upper lobes [1]. A recent study reviewing clinical manifestations and radiographic findings of patients with $M$. kansasii respiratory isolates provided further clarification [21]. Indeed, among 54 patients who met the ATS/ IDSA diagnostic criteria, 44\% exhibited the fibrocavitary form and 32\% the nodulo-bronchiectatic form [21]. Our series even showed that up to $55 \%$ of M. kansasii NTMPD developed nodular bronchiectatic forms. It is very likely that the change in ATS criteria in 2007 has led to the diagnosis of more nodular forms among M. kansasii NTM-PD.

Nearly half of $M$. xenopi were direct-smear positive for $34 \%$ cavitary forms. These results were closely related to those published in 2009 [22], reporting 61\% of positive direct examinations and $31 \%$ of cavitary forms among the 136 M. xenopi pulmonary NTM in France.

Finally, the least NTM, with some positive smearin our series, were due to $M$. fortuitum (17.6\%). In the Park study, direct examination was positive in $9 / 26$ patients (35\%) with at least three positive cultures to $M$. fortuitum [17].

Overall, $62.9 \%$ of patients were treated in our cohort, with $72.4 \%$ smear-positive specimens. The prevalence of treated patients depends on the studies. In two cohorts of MAC NTM-PD, $46.1 \%$ and $53.1 \%$ of patients received antimicrobial therapy respectively $v s 67.1 \%$ in our study of which $62.5 \%$ were smear-negative $[14,20]$. Seventy-five 
and $72.2 \%$ of $M$. kansasii and M. abscessus complex infections were treated respectively, regardless of whether the patients were smear-positive or not, which correlates well with the recognized pathogenicity of these species $[1,2,23]$. For M. xenopi, $54.6 \%$ of patients received treatment, which is more than the $32 \%$ reported in a previous French study [22]. But in the French study, one third of patients were very immunosuppressed (AIDS with less than $50 \mathrm{CD} 4 / \mathrm{mm}^{3}$ ) and a vast majority of them died before bacteriological diagnosis. Finally, only 4 (23.5\%) patients infected with $M$. fortuitum were treated. Results obtained by Park et al. showed that there was no clinical worsening or persistent positive cultures among the 25 untreated patients on a 12-month follow-up [17]. These data confirm the low pathogenicity of this species, most often responsible of colonization or transient infection that does not require generally a treatment $[1,23]$.

Our results highlight the conformity of practices of French clinicians with the ATS/IDSA guidelines. Most patients received at least three drugs during 12 months or more. These results are in contrast with those of US and European countries [5,6]. These differences could be partly explained by the study methodology and physician expertise. These physicians were randomly surveyed to generate nationally representative analyses of practice. These physicians included practitioners outside of reference centers and in non-specialized fields. These adequacy between French practices and ATS/IDSA guidelines found in our study could maybe explain the good prognosis of treated patients in our cohort in contrast to literature data especially for MAC and M. xenopi $[22,24,25]$. Indeed, a more favorable evolution was observed in our treated patients, whether or not patients are positive for direct examination. The decision to initiate a treatment should be individualized, based on clinical factors, radiological lesions, and some microbiological data (NTM specie, number and type of positive samples, and probably positive smear, often associated with cavitary lesions), as recommended by the 2 recent NTM guidelines $[2,9]$. In our study, the treatment rate was high, but we have strictly selected patients: all have ATS/ IDSA NTM disease diagnosis criteria, with a low rate of patients with an unique smear negative BAL. Moreover, all patients were clinically and radiologically symptomatic. The risk of treatment nonadherence is higher in patients with few symptoms, that is why treatment decision should be discussed according to patient and disease characteristics and with patient point of view. We have chosen to classify in more or less than 12 months, even if recommendations is 12 months after sputum conversion, because it is not easily, in the real life to have the date of sputum conversion..Finally, our lower mortality in comparison to previous published studies could be too due to patients characteristics or management differences: diagnosis or treatment prior to ATS/IDSA 2007 publication, less common use of macrolides [22]), predominance of observation without treatment [25], type of comorbidities (for example systemic immunosuppression [22] or NTM species included (especially M. xenopi $[22,25]$. Indeed, in some others studies [26, 27], outcome was mainly associated with age, comorbidities and not with species (except $M$. xenopi associated with a poor prognosis) [26]. In our study, M. abscessus appeared with the poorest prognosis. Nevertheless, it is difficult to conclude, as only few patients with $M$. abscessus have been included in this cohort $(\mathrm{n}=12)$ and no differentiation between $M$. abscessus stricto sensu and M. massiliense is available.

\section{Conclusion}

This study based on collaboration between microbiologists and clinicians gives us very complete clinical, radiological, microbiological, treatment and outcome data. The three NTM species involved in pulmonary disease in France between 2009 and 2014 were MAC, M. xenopi and $M$. kansasii. This cohort study highlighted the role of adherence to treatment guidelines in prognosis, with an individual discussion of treatment or watchful waiting. In case of treatment, this treatment for slow growing NTM, as actually recommended, should be included at least 3 drugs for a duration of 12 months after sputum conversion. The main limitation will be the realization of control samples.

\section{Abbreviations}

AIDS: Acquired Immunodeficiency Syndrom; ATS/IDSA: American Thoracic Society / Infectious Diseases Society of America; BAL: Bronchoalveolar Lavage; BTS: British Thoracic Society; HIV: Human Immunodeficiency Virus; MAC: Mycobacterium avium Complex; NTM: Nontuberculous mycobacteria; NTM-PD: Nontuberculous mycobacteria pulmonary disease.

\section{Supplementary Information}

The online version contains supplementary material available at https://doi. org/10.1186/s12890-021-01701-5.

Additional file 1. Guide to fulfill CRF.

\section{Acknowledgements \\ To MycoMed network.}

\section{Authors' contributions}

PB and CA have contributed on conception, design, acquisition, analysis, and interpretation of the data. They drafted the work, approved the final version and agreed to be accountable for all aspects of the work. OP, CM have contributed on conception, acquisition, interpretation of data, revised the work, approved the final version and agreed to be accountable for all aspects of the work. HG, JB, CB, DB1, GB, XB, EB, SB, AB, DB2, EC, FC1, DC, AC, CC GC, FC2, TD, MD1, GD, JMD, OD, MD2, AG1, MG, CG, SG, AG2, FH, GH, CK, AL, PL, SM, FM, $M M, I P, M P, L R, K R, C S, D S, D T, A V$, JV, FS have contributed to the acquisition of data for the work; and revised it critically for important intellectual content. 
They final approved the version submitted for publication; and agreed to be accountable for all aspects of the work. JD is listed as co-author, as he has contributed to the acquisition of data for the work; revised it critically for important intellectual content, and he final approved the version submitted for publication; and agreed to be accountable for all aspects of the work, just before his brutal death. We would like to keep him as co-author. All authors read and approved the final manuscript.

\section{Funding}

None.

\section{Availability of data and materials}

The datasets used and/or analysed during the current study are available from the corresponding author, Claire ANDREJAK (andrejak.claire@chu-amiens.fr)on reasonable request.

\section{Declarations}

\section{Ethics approval and consent to participate}

The study protocol was approved by the institutional review board " $\mathrm{CHU}$ Amiens Picardie ethics committee" (PI2018_843_0049) and we obtained permission from the CNIL (French national commission for informatics and freedom) as we respected the reference methodology $\mathrm{N}^{\circ} 4$, as requested by the French law (2018-155 from the French official journal)). These two approval were necessary to access the clinical and personal data of patients. The need for consent is deemed unnecessary according to national regulations (Art 1121-1 of Public Health Code). Indeed, as requested by the French law (Art 1121-1 of Public Health (ode), we have only to check the non-opposition of the patients (as it is a retrospective study, on "data" without any intervention for patients). We gave written information on the study to each patient. In case of opposition, patient was not included. The potential opposition is indicated in the medical record.

\section{Consent for publication}

Not concerned.

\section{Competing interests}

The authors declare that they have no competing interests.

\section{Author details}

${ }^{1}$ Department of Bacteriology, CHU Nantes, Nantes, France. ${ }^{2}$ Department of Bacteriology, CHU Bordeaux, Bordeaux, France. ${ }^{3}$ Department of Bacteriology, CHU Toulouse, Toulouse, France. ${ }^{4}$ Department of Bacteriology, CHU Dijon, Dijon, France. ${ }^{5}$ Department of Respiratory Diseases, CHU Tours, Tours, France. ${ }^{6}$ Department of Respiratory Diseases, Amiens University Hospital, $\mathrm{CHU}$ Amiens, 80054 Amiens Cedex 1, France. ${ }^{7}$ EA 4294 AGIR, Picardie Jules Verne University, Amiens, France. ${ }^{8}$ Department of Respiratory Diseases, CHU Dijon, Dijon, France. ${ }^{9}$ Department of Respiratory Diseases, CHU Nantes, Nantes, France. ${ }^{10}$ Department of Respiratory Diseases, CHU Bordeaux, Bordeaux, France. ${ }^{11}$ Department of Respiratory Diseases, CH Roubaix, Bordeaux, France. ${ }^{12}$ Department of Bacteriology, CHU Poitiers, Poitiers, France. ${ }^{13}$ Department of Infectious Disease, CHU Nantes, Nantes, France. ${ }^{14}$ Department of Bacteriology, AP-HP, Paris, France. ${ }^{15}$ Laboratoire Associé du Centre National de Référence des Mycobactéries et Résistance des Mycobactéries aux Antibiotiques (CNR-MyRMA), Paris, France. ${ }^{16}$ Department of Bacteriology, CH Valenciennes, Valenciennes, France. ${ }^{17}$ Department of Respiratory Diseases, CH Valenciennes, Valenciennes, France. ${ }^{18}$ Department of Bacteriology, CHU Saint Etienne, Saint Etienne, France. ${ }^{19}$ Department of Bacteriology, CHU Montpellier, Montpellier, France. ${ }^{20}$ Department of Bacteriology, CHU Besançon, Besançon, France. ${ }^{21}$ Department of Respiratory Diseases, CHU Brest, Brest, France. ${ }^{22}$ Department of Respiratory Diseases, CHU Besançon, Besançon, France. ${ }^{23}$ Department of Respiratory Diseases, CHRU Strasbourg, Strasbourg, France. ${ }^{24}$ Department of Respiratory Diseases, Hospices Civils Lyon, Lyon, France. ${ }^{25}$ Department of Bacteriology, Hospices Civils Lyon, Lyon, France. ${ }^{26}$ Department of Respiratory Diseases, CHU Limoges, Limoges, France. ${ }^{27}$ Department of Bacteriology, $\mathrm{CHU}$ Nice, Nice, France. ${ }^{28}$ Department of Respiratory Diseases, CHU Poitiers, Poitiers, France. ${ }^{29}$ Department of Bacteriology, CHU Amiens, Amiens, France. ${ }^{30}$ Department of Bacteriology, CHU Brest, Brest, France. ${ }^{31}$ Department of Bacteriology, CHRU Strasbourg, Strasbourg, France. ${ }^{32}$ Department of Bacteriology, CHU Tours, Tours, France. ${ }^{33}$ Department of Respiratory Diseases, CHU Toulouse,
Toulouse, France. ${ }^{34}$ Department of Respiratory Diseases, CHU Nice, Nice, France. ${ }^{35}$ Department of Bacteriology, CH Roubaix, Roubaix, France. ${ }^{36}$ Department of Respiratory Diseases, CHU Saint Etienne, Saint Etienne, France.

${ }^{37}$ Department of Bacteriology, CHU Limoges, Limoges, France.

Received: 26 July 2021 Accepted: 13 October 2021

Published online: 26 October 2021

\section{References}

1. Griffith DE, Aksamit T, Brown-Elliott BA, Catanzaro A, Daley C, Gordin F, Holland SM, Horsburgh R, Huitt G, lademarco MF, Iseman M, Olivier K, Ruoss S, von Reyn CF, Wallace RJ, Winthrop K, ATS Mycobacterial Diseases Subcommittee; American Thoracic Society; Infectious Disease Society of America.. An official ATS/IDSA statement: diagnosis, treatment, and prevention of nontuberculous mycobacterial diseases. Am J Respir Crit Care Med 2007;175:367-16.

2. Daley CL, laccarino JM, Lange C, Cambau E, Wallace RJ Jr, Andrejak C, Böttger EC, Brozek J, Griffith DE, Guglielmetti L, Huitt GA, Knight SL, Leitman P, Marras TK, Olivier KN, Santin M, Stout JE, Tortoli E, van Ingen J, Wagner D, Winthrop KL. Treatment of nontuberculous mycobacterial pulmonary disease: an official ATS/ERS/ESCMID/IDSA clinical practice guideline. Eur Respir J. 2020;56(1):2000535.

3. Stout JE, 1, Koh WJ, Yew WW. Update on pulmonary disease due to nontuberculous mycobacteria. Int J Infect Dis 2016;45:123-134.

4. Prevots DR, Loddenkemper R, Sotgiu G, Migliori GB. Nontuberculous mycobacterial pulmonary disease: an increasing burden with substantial costs. Eur Respir J. 2017;49:1700374.

5. Van Ingen J, Wagner D, Gallagher J, Morimoto K, Lange C, Haworth CS, Floto RA, Adjemian J, Prevots DR, Griffith DE, NTM-NET. Poor adherence to management guidelines in nontuberculous mycobacterial pulmonary disease. Eur Respir J 2017:49.

6. Adjemian J, Prevots DR, Gallagher J, Heap K, Gupta R, Griffith D. Lack of adherence to evidence-based treatment guidelines for nontuberculous mycobacterial lung disease. Ann Am Thorac Soc. 2014;11:9-16.

7. Maugein J, Dailloux M, Carbonnelle B, Vincent V, Grosset J. Sentinel-site surveillance of Mycobacterium avium complex pulmonary disease. Eur Respir J. 2005;26:1092-6.

8. Dailloux M, Abalain ML, Laurain C, Lebrun L, Loos-Ayav C, Lozniewski A, Maugein J. Respiratory infections associated with nontuberculous mycobacteria in non-HIV patients. Eur Respir J. 2006;28:1211-5.

9. Haworth CS, Banks J, Capstick T, Fisher AJ, Gorsuch T, Laurenson IF, Leitch A, Loebinger MR, Milburn HJ, Nightingale M, Ormerod P, Shingadia D, Smith D, Whitehead N, Wilson R, Floto RA. British Thoracic Society guidelines for the management of non-tuberculous mycobacterial pulmonary disease (NTM-PD). Thorax. 2017;72(Suppl 2):ii1-ii64.

10. Field SK, Fisher D, Cowie RL. Mycobacterium avium complex pulmonary disease in patients without HIV infection. Chest. 2004;126:566-81.

11. van der Werf MJ, Ködmön C, Katalinić-Janković V, KummikT, Soini $H$, Richter E, Papaventsis D, Tortoli E, Perrin M, van Soolingen D, Zolnir-Dovč $\mathrm{M}$, Ostergaard TV. Inventory study of non-tuberculous mycobacteria in the European Union. BMC Infect Dis. 2014;14:62.

12. O'Brien RJ, Geiter $\sqcup$, Snider DE Jr. The epidemiology of nontuberculous mycobacterial diseases in the United States. Results from a national survey. Am Rev Respir Dis 1987;135:1007-14.

13. Obayashi Y, Fujita J, Suemitsu I, Kamei T, Nii M, Takahara J. Clinical features of non-tuberculous mycobacterial disease: comparisons between smearpositive and smear-negative cases, and between Mycobacterium avium and Mycobacterium intracellulare. Int J Tuberc Lung Dis. 1998;7:597-602.

14. Boyle DP, Zembower TR, Reddy S, Qi C. Comparison of clinical features, virulence, and relapse among Mycobacterium avium complex species. Am J Respir Crit Care Med. 2015;191:1310-7.

15. van Ingen J. Microbiological diagnosis of nontuberculous mycobacterial pulmonary disease. Clin Chest Med. 2015;36:43-54.

16. Ryu YJ, Koh WJ, Daley CL. Diagnosis and treatment of nontuberculous mycobacterial lung disease: clinicians perspectives. Tuberc Respir Dis. 2016:79:74-84.

17. Park S, Suh GY, Chung MP, Kim H, Kwon OJ, Lee KS, Lee NY, Koh WJ. Clinical significance of Mycobacterium fortuitum isolated from respiratory specimens. Respir Med. 2008;102:437-42. 
18. Hoefsloot W, van Ingen J, Andrejak C, Angeby K, Bauriaud R, Bemer P, Beylis N, Boeree MJ, Caho J, Chihota V, Chimara E, Churchyard G, Cias R, Daza R, Daley CL, Dekhuijzen PNR, Domingo D, Drobniewski F, Esteban J, Fauville-Dufaux M, Folkvardsen DB, Gibbons N, Gomez-mampaso E, Gonzalez R, Hoffmann H, Hsueh PR, Indra A, Jagielski T, Jamieson F, Jankovic M, Jong E, Keane J, Koh WJ, Lange B, leao S, Macedo R, Mannsaker T, Marras TK, Maugein J, Milburn HJ, Mlinko T, Morcillo N, Morimoto K, Papaventsis D, Palenque E, paez-Pena M, Piersimoni C, Polanova M, rastogi N, Richter E, Ruiz-Serrano MJ, Siva A, da Silva MP, simsek H, van Soolingen D, Szabo N, Thomson R, Fernandez TT, Tortoli E, Totten SE, Tyrell G, Vasankari T, Villar M, Walkiewicz R, Winthrop KL, Wagner D. The geographic diversity of nontuberculous mycobacteria isolated from pulmonary samples: an NTM-NET collaborative study. Eur Respir J. 2013;42:1604-13.

19. Wright PW, Richard J, Wallace JR, Wright NW, Brown BA, Griffith DE. Sensitivity of fluorochrome microscopy for detection of Mycobacterium tuberculosis versus nontuberculous mycobacteria. J Clin Microbiol. 1998;36:1046-9.

20. Ito Y, Hirai T, Maekawa K, Fujita K, Imai S, Tatsumi S, Handa T, Matsumoto H, Muro S, Niimi A, Mishima M. Predictors of 5-year mortality in pulmonary Mycobacterium avium-intracellulare complex disease. Int J Tuberc Lung Dis. 2012;16:408-14.

21. Moon SM, Park Hy, Jeon K, Kim SY, Chung MJ, Huh HJ, Ki CS, Lee NY, Shin SJ, Koh WJ. Clinical significance of mycobacterium Kansasii isolates from respiratory specimens. PLoS ONE. 2015;10(10): e0139621. Doi:https://doi. org/10.1371/journal.pone.0139621
22. Andréjak C, Lescure FX, Pukenyte E, Douadi Y, Yazdanpanah Y, Laurans G, Schmit JL, Jounieaux V; Xenopi Group. Mycobacterium xenopi pulmonary infections: a multicentric retrospective study of 136 cases in north-east France. Thorax. 2009;64:291-6.

23. Aksamit TR, Philley JV, Griffith DE. Nontuberculous mycobacterial (NTM) lung disease: the top ten essentials. Respir Med. 2014;108:417-25.

24. Andréjak C, Lescure FX, Douadi Y, Laurans $G$, Smail A, Duhaut $P$, Jounieaux $\checkmark$, Schmit JL. Non-tuberculous mycobacteria pulmonary infections: management and follow-up of 31 infected patients. J Infect. 2007;55:34-40.

25. Hayashi M, Takayanagi N, Kanauchi T, Miyahara Y, Yanagisawa T, Sugita Y. Prognostic factors of $634 \mathrm{HIV}$-negative patients with Mycobacterium avium complex disease. Am J Respir Crit Care. 2012;185:575-83.

26. Andrejak C, Thomsen V $\varnothing$,Johansen IS, Riis A, Benfield TL, Duhaut $P$, Sørensen HT, Lescure FX, Thomsen RW. Non tuberculous pulmonary mycobacteriosis in Denmark. Incidence and prognostic factors. Am J Respir Crit Care Med 2010;514-21.

27. Adjemian J, Olivier KN, Seitz AE, Holland SM, Prevots DR. prevalence of nontuberculous mycobacteria lung disease in U.S. Medicare beneficiaries. Am J Respir Crit Care Med 2012;15:185:881

\section{Publisher's Note}

Springer Nature remains neutral with regard to jurisdictional claims in published maps and institutional affiliations.
Ready to submit your research? Choose BMC and benefit from:

- fast, convenient online submission

- thorough peer review by experienced researchers in your field

- rapid publication on acceptance

- support for research data, including large and complex data types

- gold Open Access which fosters wider collaboration and increased citations

- maximum visibility for your research: over $100 \mathrm{M}$ website views per year

At BMC, research is always in progress.

Learn more biomedcentral.com/submissions 